\title{
Safety of ondansetron loading doses in children with cancer
}

\author{
Susann B. Hasler • Andreas Hirt • \\ Annette Ridolfi Luethy • Kurt K. Leibundgut • \\ Roland A. Ammann
}

Received: 9 July 2007 / Accepted: 12 September 2007 / Published online: 17 October 2007

(C) Springer-Verlag 2007

\begin{abstract}
Introduction In highly emetogenic chemotherapy, the recommended dose of the serotonin-receptor antagonist ondansetron $\left(5 \mathrm{mg} / \mathrm{m}^{2} \mathrm{q} 8 \mathrm{~h}\right.$ ) may be insufficient to prevent chemotherapy-induced nausea and vomiting. In adults, ondansetron-loading doses (OLD) of $32 \mathrm{mg}$ are safe. We aimed to evaluate in children the safety of an OLD of $16 \mathrm{mg} / \mathrm{m}^{2}$ (top, $24 \mathrm{mg}$ ) i.v., followed by two doses of $5 \mathrm{mg} / \mathrm{m}^{2} \mathrm{q} 8 \mathrm{~h}$.

Materials and methods This retrospective single-center study included all pediatric oncology patients having received $\geq 1$ OLD between 2002 and 2005. Adverse events (AE) definitely, probably, or possibly related to OLD were studied, excluding AE not or unlikely related to the OLD. Associations between potential predictors and at least moderate AE were analyzed by mixed logistic regression. Results Of 167 patients treated with chemotherapy, 37 (22\%) received 543 OLD. The most common AE were hypotension, fatigue, injection site reaction, headache, hot flashes/flushes, and dizziness. At least mild AE were described in 139 OLD (26\%), at least moderate $\mathrm{AE}$ in 23 (4.2\%), and severe AE in 5 $(0.9 \%$; exact $95 \%$ confidence interval $[\mathrm{CI}], 0.4-2.1)$. Lifethreatening or lethal $\mathrm{AE}$ were not observed $(0.0 \% ; 0.0-0.6)$. At least moderate $\mathrm{AE}$ were significantly more frequent in
\end{abstract}

Results presented in part at the 20th Symposium of the Multinational Association of Supportive Care in Cancer, St. Gallen, Switzerland, June 27-30, 2007.

S. B. Hasler ' A. Hirt · A. Ridolfi Luethy $\cdot$ K. K. Leibundgut •

R. A. Ammann $(\triangle)$

Division of Pediatric Hematology/Oncology,

Department of Pediatrics, University of Bern, Inselspital,

3010 Bern, Switzerland

e-mail: roland.ammann@insel.ch female patients (odds ratio [OR] 3.5; 95\% CI 1.4-8.8; $p=$ $0.010)$, after erroneously given second OLD (17.0; 1.9-154; $p=0.012)$ and higher $24 \mathrm{~h}$ cumulative surface corrected dose $\left(1.26\right.$ per $\left.\mathrm{mg} / \mathrm{m}^{2} ; 1.06-1.51 ; p=0.009\right)$. OLD given to infants below 2 years were not associated with more frequent $\mathrm{AE}$.

Conclusions Ondansetron-loading doses of $16 \mathrm{mg} / \mathrm{m}^{2}$ (top, $24 \mathrm{mg}$ ) i.v. seem to be safe in infants, children, and adolescents.

Keywords Chemotherapy · Children .

Ondansetron loading dose $\cdot$ Nausea $\cdot$ Emesis

\section{Introduction}

Nausea and vomiting remain one of the three most distressing side effects of chemotherapy [8]. Specific serotonin (5-HT) receptor antagonists are generally accepted as the standard of care for prophylaxis of emesis $[9,12]$. In highly emetogenic chemotherapy, the recommended doses are often insufficient, however. Optimal pediatric dosing and scheduling of antiemetics remain uncertain, and large robust trials are needed [1]. Due to variation of pharmacokinetic parameters in children, higher weight-based doses of $5-\mathrm{HT}_{3}$ antagonists than those used in adults may be required for antiemetic protection [12]. The question is whether higher doses are also safe.

The standard dose of ondansetron, a selective $5-\mathrm{HT}_{3}$ receptor antagonist, is $5 \mathrm{mg} / \mathrm{m}^{2}$ (top dose, $8 \mathrm{mg}$ ) given intravenously or orally every $8 \mathrm{~h}$. In adults, ondansetron loading doses (OLD) of $32 \mathrm{mg}$ applied intravenously have been shown to be safe and well tolerated [19], while comparable data in children are rare. One prospective, random- 
ized, double-blind study found no clinical or laboratory toxicity after application of 16 ondansetron doses of $0.6 \mathrm{mg} / \mathrm{kg}$ in children, corresponding to about $18 \mathrm{mg} / \mathrm{m}^{2}$, top dose $32 \mathrm{mg}$ [18].

The aim of this retrospective single center study was to determine whether an OLD of $16 \mathrm{mg} / \mathrm{m}^{2}$ (top dose, $24 \mathrm{mg}$ ), administered intravenously before chemotherapy and followed by doses of $5 \mathrm{mg} / \mathrm{m}^{2}$ (top dose, $8 \mathrm{mg}$ ) every $8 \mathrm{~h}$, was safe in children and adolescents.

\section{Materials and methods}

Patients

Since 2002, all patients diagnosed with a malignancy treated with severely emetogenic chemotherapy at the Division of Pediatric Hematology/Oncology, Department of Pediatrics, University of Bern, Switzerland routinely received OLD. Patients receiving moderately emetogenic chemotherapy in whom nausea and emesis was not controlled by the standard dose of ondansetron, i.e., $5 \mathrm{mg} / \mathrm{m}^{2}$ (top, $8 \mathrm{mg}$ ) given orally or intravenously every $8 \mathrm{~h}$, received OLD as well.

Eligible for this retrospective single-center study were all patients up to the age of 17 years, who had received at least one OLD between January 1, 2002 and December 31, 2005. This study had been approved by the institutional review board.

\section{Definitions}

The OLD was given intravenously, $16 \mathrm{mg} / \mathrm{m}^{2}$ (top dose, $24 \mathrm{mg}$ ) over $15 \mathrm{~min}$, half an hour before starting chemotherapy. It was followed by two intravenous or oral doses of ondansetron $\left(5 \mathrm{mg} / \mathrm{m}^{2}\right.$; top dose, $8 \mathrm{mg}$ ) every $8 \mathrm{~h}$. Data on adverse events (AE) was collected for $24 \mathrm{~h}$ after administration of the OLD.

The Common Terminology Criteria for Adverse Events (CTCAE; Version 3.0) were used to specify and quantify AE [23]. Severity of AE was divided into five grades: mild, moderate, severe, life-threatening, and death due to AE. Furthermore, it was described whether AE were definitely, probably, possibly, unlikely, or not related to the OLD [14].

Chemotherapy was classified into four levels of emetogenic risk, i.e., minimal (emesis in $<10 \%$ ) like vincristine, low (10 to $30 \%$ ) like etoposide, moderate (30 to $90 \%$ ) like ifosfamide, and high (>90\%) like cisplatin [12].

\section{Data assessment}

Patient characteristics (sex, age at diagnosis, diagnosis, and relapse status), emetogenic risk of chemotherapy, and infor- mation on AE including quality, severity, and relation to OLD were extracted retrospectively from patient records.

\section{Statistical analysis}

Because of non-normally distributed data, median, interquartile range (IQR), and range were calculated. Exact BlythStill-Casella 95\% confidence intervals (CI) were calculated for proportions. The exact Fisher-Freeman Halton test was used for comparing proportions, and mixed logistic regression (penalized quasi-likelihood method) for comparison of $\mathrm{AE}$ risks between different groups. Two-sided tests were applied throughout, and $p$ values below 0.05 were considered significant. The softwares used were StatXact 6 (Cytel Software, Cambridge, MA, USA) and R 2.4.0 (R Foundation for Statistical Computing, Vienna, Austria).

\section{Results}

\section{Patients}

In the 4 years studied, 167 patients were diagnosed with cancer requiring chemotherapy, with $37(22 \%)$ of them receiving at least one OLD. The proportion of children receiving OLD was significantly lower in those with leukemia or lymphoma vs those with solid tumor within or outside the central nervous system, while there were no differences as to age at diagnosis, gender, and relapse status (Table 1). The median age of the 37 children studied here was 6.9 years when receiving their first OLD (range, 0.4 to 15.7). The smallest child weighed $4.4 \mathrm{~kg}$, with a calculated body surface area of $0.26 \mathrm{~m}^{2}$.

\section{Ondansetron-loading doses}

During the study period, these 37 patients received 543 OLD (median per patient, 12; range, 1 to 46) during 231 cycles of chemotherapy. As intended, 508 (94\%) OLD were administered intravenously, while $35(6 \%)$ were given orally. Only four $(0.7 \%)$ OLD were given as antiemetic therapy, while the remaining 539 (99.3\%) doses were applied prophylactically. As additional antiemetic medication, dexamethasone $\left(2 \mathrm{mg} / \mathrm{m}^{2} \mathrm{q} 8 \mathrm{~h}\right)$ was given in $454(84 \%)$ of the OLD, dexamethasone together with lorazepam in $12(2.2 \%)$, and lorazepam in $1(0.2 \%)$, while the OLD was administered without concurrent antiemetic medication $76(14 \%)$ times.

The median OLD was $16 \mathrm{mg}$ (IQR, 12 to 24; range, 4 to 25). The intended top dose of $24 \mathrm{mg}$, corresponding to a body surface area of at least $1.5 \mathrm{~m}^{2}$, was given 175 times $(32 \%)$, while it was exceeded once $(0.2 \% ; 25 \mathrm{mg})$. The median surface-corrected dose was $15.6 \mathrm{mg} / \mathrm{m}^{2}$ (IQR, 14.8 to 16.2 ; range, 10.7 to 20.5 ). The OLD was dosed as in- 
Table 1 Patient characteristics

\begin{tabular}{|c|c|c|c|c|}
\hline \multirow[t]{2}{*}{ Characteristic } & \multirow{2}{*}{$\begin{array}{l}\text { All patients } \\
\text { Number }\end{array}$} & \multicolumn{3}{|c|}{ Patients receiving at least one OLD } \\
\hline & & $\begin{array}{l}\text { Number } \\
\text { (proportion) }\end{array}$ & $\begin{array}{l}\text { OLD per patient: } \\
\text { median (range) }\end{array}$ & $\begin{array}{l}\text { OLD in total } \\
\text { (proportion) }\end{array}$ \\
\hline Total & 167 & $37(22 \%)$ & $12(1$ to 46$)$ & $543(100 \%)$ \\
\hline \multicolumn{5}{|l|}{ Diagnosis $(p<0.001)$} \\
\hline Leukemia & 77 & $5(6 \%)$ & $2(1$ to 18$)$ & $26(5 \%)$ \\
\hline Lymphoma & 24 & $2(8 \%)$ & $11(5$ to 16$)$ & $21(4 \%)$ \\
\hline CNS tumor & 25 & $13(52 \%)$ & $11(4$ to 18$)$ & $133(24 \%)$ \\
\hline Solid tumor outside CNS & 41 & $17(41 \%)$ & $18(4$ to 46$)$ & $363(67 \%)$ \\
\hline \multicolumn{5}{|l|}{ Age at diagnosis $(p=0.63)$} \\
\hline$<2$ years & 33 & $6(18 \%)$ & $9(4$ to 14$)$ & $52(10 \%)$ \\
\hline$\geq 2$ and $<6$ years & 47 & $11(23 \%)$ & $13(4$ to 46$)$ & $173(32 \%)$ \\
\hline$\geq 6$ and $<12$ years & 49 & $9(18 \%)$ & $8(1$ to 36$)$ & $103(19 \%)$ \\
\hline$\geq 12$ years & 38 & $11(29 \%)$ & $18(1$ to 44$)$ & $215(40 \%)$ \\
\hline \multicolumn{5}{|l|}{ Gender $(p=0.85)$} \\
\hline Female & 81 & $17(21 \%)$ & $9(1$ to 46$)$ & $220(41 \%)$ \\
\hline Male & 86 & $20(23 \%)$ & $14(1$ to 44$)$ & $323(59 \%)$ \\
\hline \multicolumn{5}{|l|}{ Relapse status* $(p=1.00)$} \\
\hline Initial diagnosis & 159 & $34(21 \%)$ & $12(1$ to 44$)$ & $479(88 \%)$ \\
\hline Relapse & 20 & $4(20 \%)$ & 17 (8 to 22$)$ & $64(12 \%)$ \\
\hline
\end{tabular}

tended, i.e., $16 \mathrm{mg} / \mathrm{m}^{2} \pm 15 \%$ (13.6 to $18.4 \mathrm{mg} / \mathrm{m}^{2}$ ), with a top dose of $24 \mathrm{mg}, 503$ (93\%) times, while doses were too low $10(1.8 \%)$ times and too high 30 (5.5\%) times (Fig. 1).

Of the 543 OLD, 528 (97\%) were followed as intended by two conventional ondansetron doses every $8 \mathrm{~h}$, while 9 $(1.7 \%)$ times only one conventional dose, and $6(1.1 \%)$ times no further ondansetron dose was administered. After three $(0.6 \%)$ OLD, a second OLD was administered erroneously within 3.5 to $6.5 \mathrm{~h}$. The median cumulative ondansetron dose over $24 \mathrm{~h}$ was $31 \mathrm{mg}$. The median cumulative surface corrected dose, aiming at $26 \mathrm{mg} / \mathrm{m}^{2}$, was $26.1 \mathrm{mg} / \mathrm{m}^{2}$ (IQR, 24.7 to 27.8 ; range, 13.5 to 36.1 ).

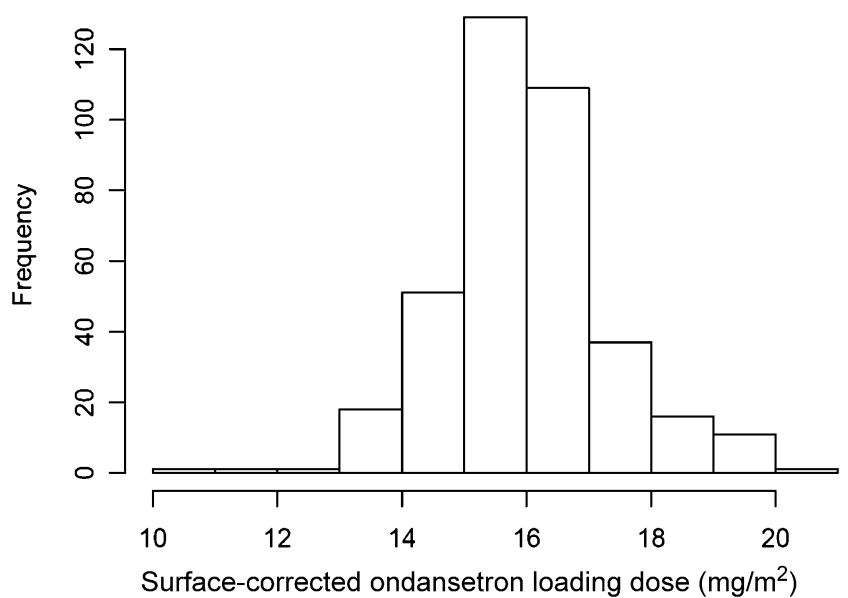

Fig. 1 Ondansetron-loading doses given to patients with a body surface area of $1.5 \mathrm{~m}^{2}$ at most (total, 375). Children with a higher surface area received the top dose of $24 \mathrm{mg}$

\section{Observed adverse events}

In total, $356 \mathrm{AE}$ were reported. There were 298 mild AE, 45 moderate $\mathrm{AE}$, and 13 severe $\mathrm{AE}$, while there were no life-threatening or lethal AE. As 190 AE were considered not or unlikely to be related to the OLD, only the remaining $166 \mathrm{AE}$ at least possibly related were further studied. Of these, 140 (84\%) AE were mild, 21 (13\%) moderate, and 5 (3.0\%) severe. The most common AE were hypotension and fatigue (31 each), injection site reaction (16), headache (15), hot flashes/flushes (14), and dizziness (11; Table 2).

In 139 OLD (25.6\%; exact 95\% CI 22.0 to 29.4 ), at least one $\mathrm{AE}$ at least possibly related to the OLD was observed. In $23(4.2 \% ; 2.8$ to 6.3$)$ of these OLD, an AE was at least moderate, and in $5(0.9 \% ; 0.4$ to 2.1$)$ of these OLD, the AE was severe. See Table 3 for details and for the respective numbers when the three OLD that were followed erroneously by a second OLD were excluded from analysis.

Of interest, OLD given to infants below 2 years were not associated with more $\mathrm{AE}$ than in older children: In infants, at least one mild $\mathrm{AE}$ at least possibly related to the OLD was recorded in 6 of 52 OLD $(12 \% ; 5$ to 23$)$, while there were no moderate or severe AE recorded in OLD in these infants.

The severe AE reported to be at least possibly related to five OLD included dizziness, headache, and abdominal pain. There were two patients experiencing severe AE probably or definitely related to an OLD: First, a girl aged 16 years, treated for medulloblastoma, developed severe dizziness plus moderate injection site reaction immediately after receiving erroneously a second OLD after $3.5 \mathrm{~h}$, leading to a cumulative 
Table 2 Adverse events

Indicated are the number of adverse events reported, and the respective proportion of OLD in parentheses

\begin{tabular}{|c|c|c|c|c|}
\hline \multirow[t]{2}{*}{ Type of AE } & \multicolumn{4}{|c|}{ Grade of Adverse Events } \\
\hline & Mild & Moderate & Severe & Total \\
\hline Hypotension & $31(5.7 \%)$ & 0 & 0 & $31(5.7 \%)$ \\
\hline Fatigue & $30(5.5 \%)$ & $1(0.2 \%)$ & 0 & $31(5.7 \%)$ \\
\hline Injection site reaction & $12(2.2 \%)$ & $4(0.7 \%)$ & 0 & $16(2.9 \%)$ \\
\hline Pain-head/headache & $8(1.5 \%)$ & $5(0.9 \%)$ & $2(0.4 \%)$ & $15(2.8 \%)$ \\
\hline Hot flashes/flushes & $12(2.2 \%)$ & $2(0.4 \%)$ & 0 & $14(2.6 \%)$ \\
\hline Dizziness & $9(1.7 \%)$ & 0 & $2(0.4 \%)$ & $11(2.0 \%)$ \\
\hline Pain-abdomen & $8(1.5 \%)$ & 0 & $1(0.2 \%)$ & $9(1.7 \%)$ \\
\hline Constipation & $7(1.3 \%)$ & $2(0.4 \%)$ & 0 & $9(1.7 \%)$ \\
\hline Allergic reaction & $7(1.3 \%)$ & $1(0.2 \%)$ & 0 & $8(1.5 \%)$ \\
\hline Pain-extremity-limb & $6(1.1 \%)$ & $1(0.2 \%)$ & 0 & $7(1.3 \%)$ \\
\hline Mood alteration-agitation & $1(0.2 \%)$ & $2(0.4 \%)$ & 0 & $3(0.6 \%)$ \\
\hline Ocular-other (impaired vision) & $1(0.2 \%)$ & $2(0.4 \%)$ & 0 & $3(0.6 \%)$ \\
\hline Pruritus & $2(0.4 \%)$ & 0 & 0 & $2(0.4 \%)$ \\
\hline Edema: head and neck & $2(0.4 \%)$ & 0 & 0 & $2(0.4 \%)$ \\
\hline Diarrhea & $2(0.4 \%)$ & 0 & 0 & $2(0.4 \%)$ \\
\hline Dysphagia & 0 & $1(0.2 \%)$ & 0 & $1(0.2 \%)$ \\
\hline
\end{tabular}

ondansetron dose of $28 \mathrm{mg} / \mathrm{m}^{2}$. Second, a 5-year-old girl treated for osteosarcoma developed severe abdominal pain $2 \mathrm{~h}$ after receiving a correctly dosed OLD.

Factors associated with the risk of adverse events

Table 4 displays that double OLD, a higher 24 h cumulative surface corrected dose, and female gender all were significantly associated with an increased frequency of moderate or severe AE. This was the case as well for a higher surfacecorrected loading dose and age above 2 years for mild, moderate, or severe AE. The other factors examined were not significantly associated with AE.

\section{Antiemetic efficacy}

Although the efficacy was not a primary endpoint, data on frequency of emesis and nausea were collected in the chart review. Complete or major control of emesis, i.e., not exceeding one episode in $24 \mathrm{~h}$, was achieved in 472 (87\%) OLD. In $393(72 \%)$ OLD, no nausea or emesis at all was noted in the charts.

\section{Discussion}

The results of this study indicate that OLD applied as described to prevent or treat chemotherapy induced nausea and vomiting in infants, children, and adolescents seem to be safe and well tolerated. In 404 of 543 (74\%) loading doses, no adverse events at least possibly related to ondansetron were reported. Side effects were usually mild in nature (116 OLD, $23 \%)$, while moderate $(18,3.3 \%)$ and severe $(5,0.9 \%)$ adverse events occurred in few OLD only.

The most commonly reported adverse events at least possibly related to the OLD in our study were fatigue and
Table 3 Adverse events at least possibly related to ondansetron-loading doses

$A E$ Adverse event; $O L D$ ondansetron-loading dose *After three $(0.6 \%)$ OLD, a second OLD had been erroneously administered within $8 \mathrm{~h}$
Type of AE Number of OLD with at least 1 AE of the specified type (proportion; exact $95 \%$ confidence interval)

\begin{tabular}{lll}
\cline { 2 - 3 } & 540 single OLD as intended* & All 543 OLD \\
\hline At least mild AE & $138(25.6 \% ; 21.9$ to 29.4$)$ & $139(25.6 \% ; 22.0$ to 29.4$)$ \\
At least probably related to OLD & $39(7.2 \% ; 5.2$ to 9.7$)$ & $40(7.4 \% ; 5.3$ to 9.9$)$ \\
At least moderate AE & $22(4.1 \% ; 2.6$ to 6.0$)$ & $23(4.2 \% ; 2.8$ to 6.3$)$ \\
At least probably related to OLD & $4(0.7 \% ; 0.3$ to 1.8$)$ & $5(0.9 \% ; 0.4$ to 2.1$)$ \\
At least severe AE & $4(0.7 \% ; 0.3$ to 1.8$)$ & $5(0.9 \% ; 0.4$ to 2.1$)$ \\
At least probably related to OLD & $1(0.2 \% ; 0.0$ to 1.0$)$ & $2(0.4 \% ; 0.1$ to 1.3$)$ \\
At least life-threatening AE & $0(0.0 \% ; 0.0$ to 0.6$)$ & $0(0.0 \% ; 0.0$ to 0.6$)$ \\
Death as an AE & $0(0.0 \% ; 0.0$ to 0.6$)$ & $0(0.0 \% ; 0.0$ to 0.6$)$ \\
\hline
\end{tabular}


Table 4 Influence of characteristics of patients and of loading doses on the risk of at least moderate adverse events

\begin{tabular}{|c|c|c|c|c|}
\hline \multirow[t]{2}{*}{ Characteristic } & \multirow{2}{*}{$\begin{array}{l}\text { Loading doses } \\
\text { Number }\end{array}$} & \multicolumn{3}{|c|}{ OLD with at least moderate $\mathrm{AE}$ at least possibly related to OLD } \\
\hline & & $\begin{array}{l}\text { Number (proportion) } / * \text { median } \\
\text { (interquartile range) }\end{array}$ & Odds ratio $(95 \% \mathrm{CI})$ & $p$ value \\
\hline \multicolumn{5}{|l|}{ Gender } \\
\hline Female & 220 & $16(7.3 \%)$ & $3.54(1.43-8.77)$ & 0.010 \\
\hline Male & 323 & $7(2.2 \%)$ & reference & \\
\hline \multicolumn{5}{|l|}{ Age at administration } \\
\hline$<2$ years & 52 & $0(0 \%)$ & $0.00(0.00-?)$ & 1.00 \\
\hline$\geq 2$ and $<6 \mathrm{y}$ & 155 & $10(6.5 \%)$ & $1.62(0.56-4.67)$ & 0.37 \\
\hline$\geq 6$ and $<12$ y & 87 & $3(3.4 \%)$ & $0.73(0.19-2.82)$ & 0.65 \\
\hline$\geq 12$ years & 249 & $10(4.0 \%)$ & reference & \\
\hline \multicolumn{5}{|l|}{ Diagnosis } \\
\hline Leukemia & 26 & $2(7.7 \%)$ & $2.74(0.53-14.2)$ & 0.24 \\
\hline Lymphoma & 21 & $2(9.5 \%)$ & $3.58(0.66-19.5)$ & 0.15 \\
\hline CNS & 133 & $9(6.8 \%)$ & $2.55(0.99-6.58)$ & 0.062 \\
\hline Solid tumors & 363 & $10(2.8 \%)$ & reference & \\
\hline \multicolumn{5}{|l|}{ Relapse status } \\
\hline Relapse & 64 & $4(6.3 \%)$ & $1.33(0.38-4.63)$ & 0.66 \\
\hline No relapse & 479 & $19(4.0 \%)$ & reference & \\
\hline \multicolumn{5}{|l|}{ Emetogenic risk of chemotherapy } \\
\hline Minimal $(<10 \%)$ & 2 & $0(0 \%)$ & $0.00(0.00-?)$ & 1.00 \\
\hline Low $(10 \%$ to $30 \%)$ & 20 & $2(10 \%)$ & reference & \\
\hline Moderate (30 to $90 \%$ ) & 316 & $12(3.8 \%)$ & $0.34(0.08-1.39)$ & 0.13 \\
\hline High $(>90 \%)$ & 205 & $9(4.4 \%)$ & $0.34(0.08-1.46)$ & 0.15 \\
\hline Loading dose $(\mathrm{mg})^{*}$ & $16.0(12.0-24.0)$ & $16.0(12.0-20.0)$ & $1.00(0.92-1.08)$ & 0.91 \\
\hline Loading dose, surface-corrected $\left(\mathrm{mg} / \mathrm{m}^{2}\right)^{*}$ & $15.6(14.8-16.2)$ & $15.6(14.8-16.4)$ & $0.90(0.65-1.25)$ & 0.52 \\
\hline Cumulative dose $(\mathrm{mg} / 24 \mathrm{~h})^{*}$ & $31.0(20.0-40.0)$ & $26.0(20.0-37.0)$ & $1.03(0.98-1.09)$ & 0.22 \\
\hline Cumulative dose, surface-corrected $\left(\mathrm{mg} / \mathrm{m}^{2} / 24 \mathrm{~h}\right)^{*}$ & $26.1(24.7-27.8)$ & $27.3(25.5-28.6)$ & $1.26(1.06-1.51)$ & 0.009 \\
\hline \multicolumn{5}{|l|}{ Application form of OLD } \\
\hline Intravenous & 508 & $22(4.3 \%)$ & Reference & \\
\hline Oral & 35 & $1(2.9 \%)$ & $0.70(0.12-4.14)$ & 0.69 \\
\hline \multicolumn{5}{|l|}{ Double loading dose } \\
\hline No & 540 & $22(4.1 \%)$ & Reference & \\
\hline Yes & 3 & $1(33.3 \%)$ & $17.0(1.88-154)$ & 0.012 \\
\hline \multicolumn{5}{|l|}{ Additional medication } \\
\hline Dexamethasone or Lorazepam & 467 & $20(4.3 \%)$ & $1.15(0.37-3.57)$ & 0.81 \\
\hline None & 76 & $3(3.9 \%)$ & Reference & \\
\hline
\end{tabular}

*Indicates median (interquartile range) are indicated for continuously measured variables

hypotension ( $6 \%$ of OLD each), headache, injection site reaction, hot flashes/flushes (3\% each) and constipation, abdominal pain, and dizziness ( $2 \%$ each). Both the incidence and spectrum of adverse events reported were similar to those of adults receiving an intravenous OLD of $32 \mathrm{mg}[16,17,19]$ and to those of children after a standard dose of $5 \mathrm{mg} / \mathrm{m}^{2}$ ondansetron, where headache was noted in 2 to $8 \%$, constipation in 1 to $3.5 \%$ and diarrhea in $2 \%$ besides rarer adverse effects like dizziness, warm feeling, somnolence, rash, and urticaria $[5,6,13,21]$.

Among the reports on OLD in pediatric patients, this is the first study with safety as primary end point. In a prospective, double-blind, randomized study, Sandoval et al.
[18] compared the antiemetic efficacy of a single high-dose $\left(0.6 \mathrm{mg} / \mathrm{kg}\right.$, corresponding to about $18 \mathrm{mg} / \mathrm{m}^{2}$, maximum dose $32 \mathrm{mg})$ with a repeated standard dose $(0.15 \mathrm{mg} / \mathrm{kg}$, maximum dose $8 \mathrm{mg}$, every $4 \mathrm{~h}$ ) in 31 pediatric oncology patients. The study suggested that single high-dose ondansetron was as efficacious as the multiple standard-dose regimen and was well tolerated. No patient experienced any clinical or laboratory toxicity (16 high doses of ondansetron applied; toxicity in $0 \%$; exact $95 \%$ CI, 0 to $20 \%$ ). Brock et al. [5] conducted a randomized, double-blind study, comparing a standard dose of 5 to $10 \mathrm{mg} / \mathrm{m}^{2}$, i.e., a medium dose of ondansetron, in 187 chemotherapy-naive children. There was no difference in the control of emesis or nausea, 
and both anti-emetic regimens were tolerated well. Four adverse events (headache in two episodes, dizziness, and warm feeling) were considered to be at least probably related to the standard dose $\left(5 \mathrm{mg} / \mathrm{m}^{2}\right)$ compared to one $\mathrm{AE}$ (headache) probably related to the medium dose of $10 \mathrm{mg} / \mathrm{m}^{2}$. In a randomized, double-blind, placebo-controlled trial, Parker et al. [15] had applied 48 OLD of $0.45 \mathrm{mg} / \mathrm{kg}$, corresponding to about $14 \mathrm{mg} / \mathrm{m}^{2}$. No analysis of adverse events was performed.

Surprisingly, girls appeared to suffer more AE than boys. Although female patients are known to have a higher incidence of chemotherapy-induced nausea and vomiting than male patients $[11,19,20]$, we do not know of any data on gender-related differences of adverse effects of ondansetron or of perceiving them.

Three times $(0.6 \%)$ a second loading dose had erroneously been given. As expected, this led to a significantly higher risk of at least moderate adverse events, as was a higher surface-corrected cumulative dose. These results show that OLD must not be arbitrarily increased. The top dose in our patients had been set to $24 \mathrm{mg}$, clearly below the OLD of $32 \mathrm{mg}$ established in adult oncology. This top dose had been exceeded only once $(0.2 \%)$. Generally, the adherence to dosing instructions was high with $93 \%$ of doses lying within the accepted range of $16 \mathrm{mg} / \mathrm{m}^{2} \pm 15 \%$.

A limitation of the present study is the retrospective design, which can lead to missing data, especially on AE. Both the physician and nurse's chart records, however, were searched through for $\mathrm{AE}$ to minimize this risk. The fact that in infants no excess of $\mathrm{AE}$ was recorded might reflect that either they are not more susceptible to side effects of OLD or that an important part of the side effects in this age group were recorded with a smaller probability than in older children better able to communicate. As might be anticipated when considering the severity of illness of this patient population, it was sometimes difficult to determine whether the adverse event was due to the underlying malignancy itself, to chemotherapy, other medication, or ondansetron. This problem, however, would remain as well in a prospectively designed study. For dexamethasone as a very frequent co-medication, potentially linked to hot flashes, dizziness, mood alteration, and edema, we did not find an increased frequency of AE.

An advantage of this study was the large sample size with 543 OLD, which allowed to calculate $95 \%$ CI for AE that are clearly smaller than those published before $[5,18]$. Even for infants below 2 years, sample size was acceptable with 52 OLD. Remarkably, few data about the use of serotonin 5-HT3 receptor antagonists in infants have been published [4]. One placebo-controlled study demonstrated that standard ondansetron dose $(0.1 \mathrm{mg} / \mathrm{kg}$, corresponding to $3 \mathrm{mg} / \mathrm{m}^{2}$ ) is well tolerated and effective in preventing postoperative nausea and vomiting in patients younger than
2 years of age [10]. In our study, OLD given to infants were not associated with more frequent $\mathrm{AE}$ described.

Chemotherapy-induced nausea and vomiting is still an important problem both in adult $[2,3,7,22]$ and pediatric oncology [9]. Besides approaches using new substances like neurokinin antagonists [22] and new ways of application like patient-controlled dosing of antiemetic drugs [9], higher than standard doses of established substances, like OLD, may help to reduce this problem.

In conclusion, we report that an ondansetron-loading dose of $16 \mathrm{mg} / \mathrm{m}^{2}$ (maximum, $24 \mathrm{mg}$ ) i.v. to prevent chemotherapy-induced nausea and vomiting in infants, children, and adolescents with cancer seems to be safe and well tolerated. In three quarters of OLD, no adverse event possibly due to the OLD occurred at all. A severe AE at least possibly related to the OLD occurred after five doses $(0.9 \%$; exact $95 \% \mathrm{CI}, 0.4$ to $2.1 \%)$. However, an upper dose limit exists, and OLD must not be increased arbitrarily. Despite the fact that this is a retrospective study, its results seem to be well-founded and clinically applicable. However, they cannot directly be applied to other 5-HT inhibitors.

\section{References}

1. Antonarakis ES, Evans JL, Heard GF, Noonan LM, Pizer BL, Hain RD (2004) Prophylaxis of acute chemotherapy-induced nausea and vomiting in children with cancer: what is the evidence? Pediatr Blood Cancer 43:651-658

2. Ballatori E, Roila F, Ruggeri B, Betti M, Sarti S, Soru G, Cruciali G, Di Maio M, Andrea B, Deuson RR (2007) The impact of chemotherapy-induced nausea and vomiting on health-related quality of life. Support Care Cancer 15:179-185

3. Ballatori E, Roila F, Ruggeri B, Porozzi S, Iannopollo M, Soru G, Cruciali G, Daniele B, Locatelli MC, Pellissier J, Deuson R (2007) The cost of chemotherapy-induced nausea and vomiting in Italy. Support Care Cancer 15:31-38

4. Berde CB, Billett AL, Collins JJ (2006) Symptom management in supportive care. In: Pizzo PA, Poplack DG (eds) Principles and practice of pediatric oncology, 5th edn. Lipincott Williams and Wilkins, Philadelphia, pp 1348-1379

5. Brock P, Brichard B, Rechnitzer C, Lanfeveld NE, Lanning M, Söderhàll S, Laurent C (1996) An increased loading dose of ondansetron: a north European, double-blind, randomised study in children, comparing $5 \mathrm{mg} / \mathrm{m}^{2}$ with $10 \mathrm{mg} / \mathrm{m}^{2}$. Eur J Cancer 32A:1744-1748

6. Culy CR, Bhana N, Plosker GL (2001) Ondansetron: a review of its use as an antimetic in children. Paediatr Drugs 3:441-479

7. Davis M, Maida V, Daeninck P, Pergolizzi J (2007) The emerging role of cannabinoid neuromodulators in symptom management. Support Care Cancer 15:63-71

8. de Boer-Dennert M, de Wit R, Schmitz PI, Djontono J, v Beurden V, Stoter G, Verweij J (1997) Patient perceptions of the sideeffects of chemotherapy: the influence of 5HT3 antagonists. Br J Cancer 76:1055-1061

9. Jones E, Tatsuki K, Ho RH, Kuttesch J, Shankar S, Whitlock JA, Cartwright J, Frangoul H (2007) Safety and efficacy of a continuous 
infusion, patient-controlled antiemetic pump for children receiving emetogenic chemotherapy. Pediatr Blood Cancer 48:330-332

10. Khalil SN, Roth AG, Cohen IT, Simhi E, Ansermino JM, Bolos ME, Coté CJ, Hannallah RS, Davis PJ, Brooks PB, Russo MW, Anschuetz GC, Blackburn LM (2005) A double-blind comparison of intravenous ondansetron and placebo for preventing postoperative emesis in 1- to 24-month-old pediatric patients after surgery under general anesthesia. Anesth Analg 101:356-361

11. Komada Y, Matsuyama T, Takao A, Hongo T, Nishimura Y, Horibe K, Sakurai M (1999) A randomised dose-comparison trial of granisetron in preventing emesis in children with leukaemia receiving emetogenic chemotherapy. Eur J Cancer 35:10951101

12. Kris MG, Hesketh PJ, Somerfield MR, Feyer P, Clark-Snow R, Koeller JM, Morrow GR, Chinnery LW, Chesney MJ, Gralla RJ, Grunberg SM (2006) American Society of Clinical Oncology guideline for antiemetics in oncology: update 2006. J Clin Oncol 24:2932-2947

13. Nahata MC, Hui LN, Koepke J (1996) Efficacy and safety of ondansetron in pediatric patients undergoing bone marrow transplantation. Clin Ther 18:466-476

14. National Cancer Institute, Cancer Therapy Evaluation Program (2004) NCI Guidelines: adverse event reporting requirements. www.ctep.cancer.gov

15. Parker RI, Prakash D, Mahan RA, Giugliano DM, Atlas MP (2001) Randomized, double-blind, crossover, placebo-controlled trial of intravenous ondansetron for the prevention of intrathecal chemotherapy-induced vomiting in children. J Pediatr Hematol Oncol 23:578-581

16. Perez EA, Hesketh P, Sandbach J, Reeves J, Chawla S, Markman M, Hainsworth J, Bushnell W, Friedman C (1998) Comparison of single-dose oral granisetron versus intravenous ondansetron in the prevention of nausea and vomiting induced by moderately emetogenic chemotherapy: a multicenter, double-blind, randomized parallel study. J Clin Oncol 16:754-760

17. Ruff P, Paska W, Goedhals L, Pouillart P, Riviere A, Vorobiof D, Bloch B, Jones A, Martin C, Brunet R (1994) Ondansetron compared with granisetron in the prophylaxis of cisplatin-induced acute emesis: a multicentre double-blind, randomised, parallelgroup study. Oncology 51:113-118

18. Sandoval C, Corbi D, Strobino B, Fevzi Ozkaynak M, Tugal O, Jayabose S (1999) Randomized double-blind comparison of single high-dose ondansetron and multiple standard-dose ondansetron in chemotherapy-naive pediatric oncology patients. Cancer Invest 17:309-313

19. Seynaeve C, Schuller J, Buser K, Porteder H, van Belle S, Sevelda P, Christmann D, Schmidt M, Kitchener H, Paes D, de Mulder PHM (1992) Comparison of the anti-emetic efficacy of different doses of ondansetron, given as either a continuous infusion or a single intravenous dose, in acute cisplatin-induced emesis. A multicentre, double-blind, randomised, parallel group study. Br J Cancer 66:192-197

20. Small BE, Holdsworth MT, Raisch DW, Winter SS (2000) Survey ranking of emetogenic control in children receiving chemotherapy. J Pediatr Hematol Oncol 22:125-132

21. Stevens RF (1991) The Role of ondansetron in paediatric patients: a review of three studies. Eur J Cancer 27:S20-S22

22. The Antiemetic Subcommittee of the Multinational Association of Supportive Care in Cancer (MASCC) (2006) Prevention of chemotherapy- and radiotherapy-induced emesis: results of the 2004 Perugia International Antiemetic Consensus Conference. Ann Oncol 17:20-28

23. US Department of Health and Human Services (2003) Common Terminology Criteria for Adverse Events v3.0 (CTCAE) 